\title{
LA LEXICOGRAFÍA INFORMAL REGIONALISTA: NOCIÓN Y ALGUNOS CASOS DEL ÁMBITO COSTARRICENSE ACTUAL
}

\author{
Regionalist informal lexicography: Concept and some cases \\ of the Costa Rican current scope
}

\section{Mario Hernández Delgado*}

\begin{abstract}
RESUMEN
Luego de caracterizar y discutir la noción que, para efectos de este trabajo, llamaremos lexicografía informal, se define la lexicografía informal regionalista como la lexicografía informal que describe los usos, sentidos o significados de un vocabulario que comparte la misma restricción diatópica y cuyo producto se publica en forma de obras unitarias y autónomas. Seguidamente, se establece la efectiva existencia de una lexicografía informal regionalista en Costa Rica, para lo cual se exponen los casos de cuatro publicaciones que encontramos en el medio nacional (dos en soporte impreso y dos en soporte electrónico) y que se seleccionaron a manera de ejemplos. De estas obras, tomadas en su conjunto, se llama la atención sobre determinadas peculiaridades e inconsistencias que pueden presentar en el título, el prólogo o el cuerpo de "definiciones", características que se interpretan como manifestaciones de su informalidad. El artículo termina con una serie de consideraciones que tienden a mostrar que el problema fundamental de estas obras, y que se radia en problemas más específicos, parece surgir del afán de sus autores por calcar los procedimientos y estructura de las obras formales sin poseer conocimientos ni experiencia suficientes para ello, sino que procediendo por mera intuición. Para finalizar, se hace énfasis en la necesidad de estudiar con más detalle y profundidad el fenómeno de los repertorios lexicográficos informales en el marco de una metalexicografía de alcances amplios.
\end{abstract}

Palabras clave: Lexicografía, lexicografía costarricense, lexicografía informal, lexicografía regionalista, metalexicografía. 


\begin{abstract}
After characterizing and discussing the notion that, for the purposes of this work, we will call informal lexicography, informal regionalist lexicography is defined as informal lexicography that describes the uses, senses or meanings of a vocabulary that shares the same diatopic restriction and whose product is published as unitary and autonomous works. Then, by means of four cases that can be found in the national environment (two in printed me electronic media) and that were selected as examples, the actual existence of informal regionalist lexicography in Costa Rica is shown. From these works, taken as a whole, we draw the attention upon several peculiarities and inconsistencies that could be found in the title, the prologue or the corpus of "definitions". These characteristics are interpreted as expressions of their informality. The article ends with a number of considerations that tend to show that the fundamental problem of these works, and that is spread in more specific problems, seems to rise from the eagerness of its authors to imitate the procedures and structure of the formal works without having neither enough knowledge nor experience to do this, but by mere intuition. To finish, the emphasis is made on the need to explore in more detail and depth the phenomenon of informal lexicographic lists in the framework of a broad scope metalexicography.
\end{abstract}

Key Words: Lexicography, Costa Rican lexicography, informal lexicography, regionalist lexicography, metalexicography.

\section{Introducción}

Parte de los esfuerzos de la lexicografía por consolidarse como disciplina plena se han dirigido a lograr que se le conciba no solo como una actividad relacionada con la confección de diccionarios, sino precisamente como aquella cuyo fin es hacerlos de acuerdo con criterios científicamente fundamentados ${ }^{1}$. El planteamiento, discusión y difusión de sus métodos y nociones ha dado como resultado la producción de diccionarios, enciclopedias y otros compendios de descripciones léxicas en las que fácilmente se reconoce la rigurosidad propia de la mano experta. Muchas de esas publicaciones, identificadas en ocasiones con entidades rectoras de la lengua o con casas editoriales de prestigio, pueden llegar incluso a obtener el favor del público (especializado, estudiantil o general, según a quién vaya dirigida cada publicación) hasta el punto de constituirse en obras casi obligatorias para la consulta de usos y significados.

Sin embargo, es un hecho la existencia de una actividad en cierto modo paralela a la de la lexicografía científica. Las publicaciones resultantes, a pesar de estar realizadas por personas sin conocimientos especializados en investigación, análisis y registro de los fenómenos lingüísticos, y en las cuales es común la ausencia o pobreza de rigor procedimental, no dejan de tener determinadas semejanzas con las obras tradicionalmente reconocidas como representativas de la práctica lexicográfica. Semejanzas como las siguientes: a) parten de una compilación de palabras, aunque a veces también pueden incluir construcciones más complejas con diversos grados de fijación o rigidización (como paremias, fraseologismos, conlocaciones); b) cada una de esas unidades se presenta con una descripción de sus usos, sentidos o significados; y c) el conjunto de unidades informativas se presenta estructurado o semiestructurado en un orden generalmente alfabético (a la manera de un diccionario semasiológico), aunque a veces la organización puede estar establecida, al menos de forma parcial, con base en subcampos léxicos o semánticos (a la manera de un diccionario onomasiológico).

La presencia de esos tipos de repertorios, que llamaremos informales, no es desconocida para los especialistas en lexicografía, por más que la escasa discusión sobre el asunto pueda dar esa impresión. Basta tomar en cuenta que dentro de esta especie se cuentan muchos (si no la mayoría) de los trabajos que se conocen con el nombre de glosarios. Estos parecen ser, de hecho, los ejemplares de este tipo que han gozado de mejor consideración por parte de los diccionaristas, tanto por razón de que 
muchas veces se han constituido en fuentes de nomenclatura, sentidos, usos y ejemplos, como por una especie de honradez histórica, ya que, aun antes de existir los diccionarios pensados en el sentido moderno, junto a léxicos y vocabularios ya había glosarios ${ }^{2}$.

Aun así, la posición de la lexicografía de mayor rigor formal sobre el estatus de los glosarios no parece estar aún suficientemente definida. A veces parece haber hasta una ambivalencia que podemos encontrar incluso en especialistas del más alto nivel, como es el caso del lexicógrafo Ignacio Ahumada Lara, uno de los analistas de la problemática diccionariológica que cuenta con mayor prestigio en el contexto de discusión de habla hispana.

Concretamente, su trabajo Los glosarios escondidos: contribución a la bibliografía sobre las hablas andaluzas, que aparece como capítulo 7 de su libro Estudios de lexicografía regional del español (Ahumada, 2000), comienza con las siguientes palabras [las negritas no son del original]:

El glosario, como obra lexicográfica que es, encuentra su justificación en la teoría lingüística cuando oponemos los conceptos de variedad lingüística (sincronía) y cambio lingüístico (diacronía) al sistema lingüístico (...). (Ahumada, 2000: 117).

Pero termina con estas:

El estatuto de glosario con que tipificamos estas colecciones de voces técnicas y dialectales no otorga a los materiales recogidos un grado de calidad equiparable a las compilaciones rigurosas. La técnica lexicográfica, en la mayoría de los casos, deja mucho que desear, pues las pretensiones de sus recopiladores nunca son de carácter lexicográfico, sino de índole práctica (...). (Ahumada, 2000: 125). ${ }^{3}$

Este detalle, en todo caso, no afecta la línea general de su artículo, que apunta a reafirmar la conveniencia de no olvidar que en lugares recónditos de libros y bibliotecas puede haber compilaciones de conjuntos léxicos que, sobre todo cuando incluyen explicaciones de sus usos y significados, pueden ser aprovechables por los creadores de diccionarios.

Otro autor, Pérez (2007), hace una exposición más enfática sobre la actitud abiertamente discriminatoria de la lexicografía tradicional respecto de ciertas recopilaciones que esta valora como marginales. Entre otras cosas, afirma lo siguiente:

No deja de llamar la atención la poca importancia
que la investigación lexicográfica ha dado a las
relaciones que considera ajenas a los objetivos
capitales trazados por su propia actividad. (...) El
desapego de los estudiosos hispanoamericanos,
en concreto, no deja de llamar la atención por lo
fugaz de su dedicación al tema. Resalta, aún más,
el hecho de que conociéndose la existencia de este
tipo de repertorios, apenas se les considere como
especies curiosas o museísticas -en todo caso,
periféricas- de la actividad descriptora del léxico
(Pérez, 2007: 138).

El interés de Ahumada (2000) y Pérez (2007) por otorgar un espacio a la discusión de tales expresiones lexicográficas marginales resulta, por supuesto, valioso en el contexto de la problemática lexicográfica en general, sobre todo porque en alguna medida refresca el debate en torno al objeto u objetos que caen dentro del ámbito de estudio de la disciplina.

Sin embargo, hay que notar que sus exposiciones -la del primero más contenida, la del segundo más apasionada- tienden fundamentalmente a reivindicar el valor del glosario dependiente (es decir, el que se presenta como apéndice explicativo del léxico de una obra) y de otros tipos de compilaciones de difícil acceso para el investigador, pues todas esos pequeños trabajos son potenciales fuentes de información para la labor lexicográfica.

En el caso de Ahumada (2000), trabaja con el concepto de glosarios escondidos, los cuales consisten en compilaciones principalmente de vocablos técnicos (por ejemplo, de artes $u$ oficios), de voces dialectales y de arcaísmos, normalmente con la explicación de los significados o usos de cada unidad. Además, y aunque la noción también sería aplicable a otros universos de voces especiales (como jergas, argots o variedades estilísticas), por 
motivos más bien fácticos que teóricos nunca sería aplicable a léxico general. El nombre de glosarios escondidos es justificado por el investigador de esta manera:

\begin{abstract}
Los glosarios o vocabularios de voces regionales cuando los hubo-, de cualquier arte o técnica y los glosarios de arcaísmos en las ediciones humanísticas de obras literarias han servido de fuente al trabajo lexicográfico, al diccionario monolingüe. Otra cosa es el acceso por parte del lexicógrafo a esos glosarios o vocabularios. Al tratarse de trabajos menores, su dispersión hace que, en la mayoría de los casos, no se tenga conocimiento de ellos. No es misión sino de la investigación filológica y lingüística proporcionar la información necesaria sobre los mismos (Ahumada: 118-19).
\end{abstract}

Y, más adelante:

Hablamos de glosarios escondidos porque un tratado de botánica, apicultura, música o arquitectura que contenga un glosario queda mucho más lejos del lexicógrafo que la edición de un vocabulario o de un clásico de nuestra literatura. (idem)

La idea es desarrollada más extensamente por Pérez (2007). Por ejemplo, hablando del contraste entre la dinámica del mundo de las grandes obras (básicamente del género de los diccionarios, tesoros, enciclopedias...) respecto del de los textos pequeños y subsidiarios, afirma que:

Viviendo a expensas de libros de historia, de novelas, de poemarios, de memorias, de crónicas, de libros de viajes, de tratados científicos y, entre tantos otros, de manuales tecnológicos, estos repertorios, aparentemente marginales $\mathrm{y}$, sin duda, marginados de la investigación lexicográfica, están mostrándonos el ritmo y el palpitar de la disciplina con una vitalidad que, paradójicamente, no siempre encontramos en las producciones centrales agrupadas emblemáticamente bajo los grandes dominios de la producción lexicográfica, Contrariamente, los pequeños dominios constituyen un caudal muy poderoso de la actividad lexicográfica, dibujando un trazado de múltiples posibilidades y con incontables floraciones en el que textos subsidiarios y aportes infusos lucen como haberes de la disciplina lexicográfica en cualquiera de sus intenciones descriptivas (Pérez, 2007: 141).
La actitud con que desarrollamos el presente estudio sigue la perspectiva de los dos autores que hemos venido citando respecto de los glosarios y otras especies de repertorios menores (incluyendo lo relativo a las limitaciones y eventual utilidad de estas obras), pero más especialmente la de Pérez (2007), que encontramos muy bien resumida en el siguiente párrafo:

Requieren estas producciones de una mirada que las despoje de su aparente marginalidad, del desdén del especialista rutinario y de la inexacta creencia general que las entiende como contribuciones prescindibles para entender, frente a las grandes realizaciones, el desarrollo de la lexicografía. Contrarios a estas ideas, estamos convencidos de la necesidad de estudiar estos pequeños dominios que, por una parte, nos permitirán calibrar el sentido de los grandes y, por otra, adquirir una visión del conjunto de la situación lexicográfica con valoraciones críticas de gran alcance (Pérez, op. cit.: 141).

\section{Objetivos}

En lo que respecta al estudio académico de los repertorios informales, en su mayor parte se ha concentrado en recolectar y comentar colecciones específicas utilizadas como fuentes para la recuperación de léxicos de áreas particulares o de arcaísmos. Además, se han trabajado con preferencia los glosarios literarios, posiblemente porque en ellos se ha encontrado más afinidad con el concepto de "autoridades" tan preciado para la lexicografía tradicional.

Sin embargo, cualquier búsqueda básica demostrará que no es difícil encontrar, tanto en el medio impreso como de internet, recopilaciones de vocablos escritas por personas que carecen de formación para el análisis y descripción sistemática de la lengua, en particular en lo tocante a la confección de definiciones y obras compilatorias.

El interés de este trabajo es aproximarse al estudio, desde una perspectiva crítica, de algunas de estas manifestaciones que se pueden encontrar en el medio costarricense, 
específicamente de las que tratan sobre léxico regional $-\mathrm{o}$, al menos, percibido por los autores como tal, sea que se apliquen o no criterios diferenciales o contrastivos estrictos-.

Para esto, después de concretar los rasgos característicos del objeto de estudio y de seleccionar algunas obras de esta categoría que se pueden encontrar en el medio costarricense, se mostrarán algunas peculiaridades e inconsistencias de esos trabajos vinculadas con su carácter informal. En otras palabras, los objetivos de lo que se va a exponer a continuación son:

a. Plantear definiciones operativas que permitan determinar cuándo estamos ante una obra de lexicografía informal y, en particular, ante una obra de lexicografía informal regionalista.

b. Mostrar algunos casos del ámbito costarricense actual que pueden ser considerados ejemplos de lexicografía informal regionalista.

c. De estas obras, estudiar algunas características relevantes que muestren cómo se manifiesta su "informalidad".

\section{Noción de lexicografía informal regionalista}

La noción de partida para este trabajo será la de lexicografía informal, que vamos a entender como aquella actividad que tiene por finalidad la descripción de los usos o significados de un conjunto de unidades léxicas (incluyendo, eventualmente, unidades fraseológicas o paremiológicas), típicamente seleccionadas estas según determinados criterios de restricción ${ }^{4}$, que es realizada por personas que no acreditan públicamente poseer conocimientos especializados en análisis y descripción de los diferentes componentes de la lengua, y cuyo producto se plasma en documentos escritos.

Debemos aclarar que preferimos hablar de lexicografía informal en vez de otra posibilidad que acude con rapidez a la mente, como es lexicografía aficionada, para evitar que la expresión se vaya a interpretar de entrada en dirección peyorativa, lo cual nunca podría ser coherente con un examen crítico ${ }^{5}$.

Con respecto a la expresión repertorios informalizados de Pérez (2007), no la adoptamos para evitar la posibilidad de que se entienda que la informalidad de tales obras resulta de una acción intencional de informalización, lo cual no necesariamente sería cierto. En su lugar, cuando necesitemos referirnos a los productos de la lexicografía informal, los mencionaremos como obras, repertorios, etc. (lexicográficos) informales.

Una vez establecidos los criterios que especifican los repertorios lexicográficos informales, podemos notar que los ejemplares que componen tal clase son realmente más que los aceptados por la lexicografía más tradicionalista. Entre ellos habría que contar, por poner algunos ejemplos y sin ánimo de exhaustividad: a) los glosarios que describen el léxico de una obra, especialidad, actividad, etc., siempre que no sean escritos por lingüistas o lexicógrafos; en particular, los glosarios escondidos; b) las secciones de libros técnicos o de cualquier dominio de conocimientos en las que se explica a los lectores el vocabulario propio de la especialidad -a diferencia de la noción tradicional de glosario, estas secuencias informativas pueden presentarse en notas, apartados intercalados o simplemente estar dispersas dentro del texto mayor; c) artículos o secciones de leyes y otros instrumentos normativos en los que se establecen, por vía de estipulación ${ }^{6}$, los significados precisos de los términos que aparecen en el respectivo instrumento; d) artículos periodísticos dedicados a la descripción de algún conjunto léxico; e) refraneros, f) obras de regionalismos publicadas por personas sin formación especializada en lingüística ni lexicografía; g) repertorios de autoría anónima o de autoría colectiva que se hallan en foros y otros sitios de socialización por internet; etc.

Sobre la base de la noción anterior, definiremos la lexicografía informal regionalista, objeto concreto de este estudio, 
como la lexicografía informal que describe los usos o significados de un vocabulario que comparte la misma restricción diatópica y cuyo producto se publica en forma de obras unitarias y autónomas ${ }^{7}$.

En relación con la restricción diatópica, nada impide que el vocabulario se seleccione conjunta o simultáneamente con otros tipos de restricciones, sean diastráticas, diafásicas o de otro tipo. Hay que tomar en cuenta que la aplicación de este criterio por parte de los autores de esas obras se da normalmente en forma intuitiva y subjetiva, dada su escasa o nula formación especializada en lexicografía.

En cuanto al requisito de autonomía de la obra, hay que notar que este lleva a excluir a los glosarios dependientes que describen el léxico regional de una obra literaria, así como a cualquier otro texto cuya existencia esté subordinada a la de un trabajo mayor ${ }^{8}$. De este modo, se incluyen en esta categoría solamente los repertorios cuya intención es explicar un inventario de léxico regional por el solo hecho de ser este regional, y no de léxico regional porque pueda ser el que ofrezca más dificultad a determinadas personas para la comprensión de una obra. Esa opción consciente y primaria por lo regional es lo que hemos intentado reflejar con la especificación "regionalista", en lugar de alguna otra más neutra, como, por ejemplo, "regional".

\section{Casos del ámbito costarricense actual}

Lo primero que hay que reconocer es, por lo tanto, que la lexicografía informal regionalista es una actividad real, es decir, que efectivamente existe; en particular, en el ámbito nacional de Costa Rica. Es, además, una actividad que, considerada en forma global, muestra un dinamismo relativamente amplio, lo cual probablemente haya sido favorecido, al menos en parte, por el hecho de recurrir a la publicación en internet, sobre todo en sitios de socialización (como "foros" y blogs). El carácter altamente interactivo de estos espacios, así como la ausencia de la mayoría de las limitaciones prácticas y editoriales inherentes a la obra impresa, pueden favorecer el que los aportes de quienes consultan y comentan las compilaciones puedan, si fuera del caso, ser integrados por los autores a los inventarios en un corto plazo, o sencillamente ser apreciados por el conjunto de los lectores.

Aunque para mostrar existencia estrictamente sería suficiente la presentación de un solo caso, a continuación voy a considerar una pequeña muestra de cuatro trabajos del ámbito costarricense actual, seleccionados a manera de ejemplos, y a verificar que cumplen las condiciones para ser considerados repertorios de lexicografía informal regionalista. Estos son:

a) En soporte impreso:

1. Mil y tantos tiquismos: costarricensismos (1 ${ }^{\mathrm{a}}$. ed.), de Luis Ferrero Acosta (2002).

2. A lo tico: Costarriqueñismos y otras vainas ( $4^{\mathrm{a}}$. ed.), de Alf. A. Giebler Simonet (2011).

b) En soporte electrónico (internet) ${ }^{9}$ :

3. Lenguaje popular y usual de Costa Rica, de Silvia Janer (s.f.).

4. Por la gran puta, ¡qué mal que hablamos!, de Dennis Meléndez Howell (2011).

A continuación, pasamos a verificar que cumplen las condiciones establecidas para ser consideradas representantes de la categoría en estudio:

\subsection{Sobre la restricción regional}

Con respecto a la restricción al ámbito local de Costa Rica, en los casos de Ferrero (2002), Giebler (2011) y Janer (s.f.) es evidente en el título mismo:

En cuanto a Ferrero, que incluye 1.450 artículos, se sirve a la vez de los vocablos tiquismo y costarricensismo. Sobre el primero, en el prólogo (Ferrero, op. cit:: $x$ ) indica: "Prefiero el término tiquismo en vez del 
académico costarriqueñismo, porque a Costa Rica se le conoce como Tiquicia y a nosotros como ticos" - a todas luces, esto denota una falta de dominio de la noción de registro-. Luego, en el artículo correspondiente a tiquismo, lo describe de la siguiente manera: "Voz utilizada por los ticos en el habla popular. El adjetivo costarriqueño no es utilizado por el pueblo" (ibid.: 219). Sobre el segundo, simplemente se pregunta (también en el prólogo, idem) “ipor qué no decir COSTARRICENSISMO?".

Por su parte, Giebler (2011), que registra alrededor de 1.800 entradas, utiliza sin problemas el sustantivo que reconoce el DRAE, costarriqueñismo -definido en este último como "vocablo, giro o locución propios de los costarricenses"-, reforzándolo con la locución coloquial "A lo tico". En el caso de Janer (522 entradas), opta por expresar la restricción regional con una frase preposicional no marcada: "Lenguaje popular y usual de Costa Rica".

En lo que respecta a la publicación de Meléndez (con 1.370 artículos), no es en el título donde encontramos la condición local de su vocabulario, sino en las palabras que presenta a manera de introducción al inventario propiamente dicho. Es conveniente notar que, además del rasgo diatópico, afirma tomar en cuenta también vocablos con algunas especificidades diastráticas. De hecho, parece ser que, para Meléndez, ciertos registros (en este caso "poladas" y "maiceradas") pueden tener el efecto de revestir de prototipicidad el léxico regional costarricense:

Este listado de palabras con sus definiciones no tiene otro objetivo más allá que dar una interpretación de la forma en que el tico usa muchas palabras, y las nuevas que ha creado, para enriquecer y dar más colorido a su comunicación oral. Incluye, pachuquismos (lenguaje de los pachucos), regionalismos, costumbrismos y costarriqueñismos auténticos (poladas y maiceradas). (Meléndez, 2011).

\subsection{Sobre las calidades de los autores}

Sobre los autores, hasta donde hemos podido investigar, ninguno acredita una formación o actividad profesional en lexicografía ni lingüística:

A Luis Ferrero, sus biógrafos lo resaltan como ensayista, escritor prolífico (autor de alrededor de 100 libros y muchas más publicaciones menores) e investigador autodidacta en temas de folclorística, cultura e historia costarricenses. Entre sus obras se cuentan biografías, estudios sobre arte, cultura y sociedad precolombinos de Costa Rica, críticas artísticas y literarias, y otros muchos temas. También ha ocupado cargos en entidades públicas relacionadas con patrimonio y difusión cultural. Sobre sus estudios formales, nunca terminó la secundaria, aunque por su labor cultural fue reconocido con múltiples distinciones a nivel nacional e internacional, entre ellas, los premios Aquileo J. Echeverría y Magón; además, la Universidad Nacional a Distancia (UNED) de Costa Rica le concedió el Doctorado Honoris Causa en el año $2000^{10}$.

En cuanto a Dennis Meléndez Howell, en la Universidad de Costa Rica obtuvo sendos títulos a nivel de grado en las carreras de Matemáticas y Economía. Posteriormente obtuvo en Chile una maestría en la especialidad de Desarrollo Económico y luego un doctorado en Economía en Estados Unidos, con especialidad en Comercio Internacional y Teoría Monetaria. En lo profesional, ha sido perito matemático actuarial y ha ejercido la docencia tanto en matemáticas como en diversas ramas de la Economía. También ha ocupado cargos directivos de niveles medios y altos en diversas entidades nacionales e internacionales. Desde el 2010, y por un período de seis años, es el Regulador General de la República. Además, tiene a su haber múltiples publicaciones relacionadas con sus estudios y profesión, además de otra cantidad en temas anecdóticos y de divulgación ${ }^{11}$.

Con respecto a Janer y Giebler, la búsqueda de información biográfica no ha sido tan afortunada. De Alf A. Giebler Simonet, sólo podemos decir que aparentemente es ingeniero $^{12}$, aunque no hemos podido determinar el área, y que sus actividades profesionales 
lo mantienen viajando constantemente fuera del país. Además de "A lo tico...", ha escrito un libro de ensayos en el que hace reflexiones sobre temas variados. De Silvia Janer no hemos logrado hallar ningún dato en medios públicos relativos a su formación; en todo caso, no parece haber testimonio de acceso abierto que apunte a que tenga conocimientos especializados que la acrediten como diccionarista o algo afín.

\subsection{Sobre la autonomía de las obras}

En ninguna parte de las cuatro publicaciones se indica que estén glosando el vocabulario de otra obra, por lo que se pueden considerar autónomas.

\section{Características generales}

En lo que sigue, se estudiarán algunas características generales de estas obras. Con la idea de establecer algunas formas en que se refleja su "informalidad", se hará énfasis en determinadas peculiaridades e inconsistencias. Para esto, se considerará cada una de estas publicaciones como dividida, en principio, en tres partes secuenciales, que son: a) el título, b) el prólogo (o su equivalente) y c) el cuerpo de descripciones o "definiciones". Cada una de estas partes se examinará por separado, pero globalmente respecto del conjunto de obras estudiadas. Además, los comentarios se harán sobre todo en términos cualitativos.

En cuanto al cuerpo de definiciones, se examinarán tres aspectos: a) macroestructura y criterios de lematización, b) tratamiento de la información enciclopédica y c) particularidades de la ejemplificación (si la hay). Los problemas que presenten también serán considerados desde una perspectiva general e ilustrados con uno o varios ejemplos extraídos del conjunto de las obras. Para la discusión se tomarán como base de referencia (pero no de evaluación) algunos conceptos y parámetros usuales en la lexicografía tradicional, los cuales se aplicarán por analogía.

\subsection{El título}

Como sabemos, la función primaria del título de una obra escrita es delimitar aquello de lo que esta tratará. Es, en otras palabras, un recurso metadiscursivo que dará a cualquier potencial lector una idea sobre el tipo de contenido de la obra, actuando así como una especie de tarjeta de presentación.

En el caso de Por la gran puta, iqué mal que hablamos!, nombre del trabajo de Meléndez (2011), la información que ofrece sobre el probable contenido no es tan transparente ${ }^{13}$; sin embargo, como ya se ha dicho, la especificación sí aparece en forma bastante clara en el título de los otros tres:

- Mil y tantos tiquismos: costarricensismos, de Ferrero (2002),

- A lo tico: Costarriqueñismos y otras vainas, de Giebler (2011) y

- Lenguaje popular y usual de Costa Rica, de Janer (s.f.).

Ahora bien, aparte de la demarcación del tema, el título puede ofrecer muchas veces otro tipo de información, adicional a la denotativa. En particular, el registro, y en general cualquier rasgo diasistemático, pueden transmitir al lector información sintomática sobre el autor. El empleo en el título de lenguaje no estándar, es decir, marcado, utilizado por los miembros del grupo en el cual se encuentran los potenciales lectores de las obras, parece ser una estrategia afín al fenómeno que Labov (1966), Trudgill (1972, 1992) y otros han estudiado bajo el nombre de prestigio encubierto, concepto que Trudgill (1992: 20-21) explica como "las connotaciones favorables que las formas no estándares, de bajo estatus social o «incorrectas» tienen para muchos hablantes". La idea es que el uso de lenguaje marcado -y sobre todo el correspondiente a variedades vernáculas regionales- beneficia microsocialmente a quien lo emplea en la medida en que induce en la comunidad de uso sentimientos de identidad, solidaridad, empatía y aceptación hacia aquel. El 
mensaje implícito sería algo así como: "Yo soy uno de ustedes".

Por otro lado, encontrar identificación y empatía en el público meta no valdría de mucho si no fuera porque estas pueden, por un lado, favorecer el interés de un potencial lector por la obra y, por otro, ayudar a la credibilidad del autor. El mensaje, más completo, sería algo parecido a: "Yo soy uno de ustedes, (por lo tanto,) cuando hablo de su forma de hablar, sé de lo que hablo" 14 .

En nuestro caso, tres de los títulos optan por el empleo de léxico marcado: tiquismo, tico y vaina son percibidos por los respectivos autores como costarriqueñismos y definidos en sus obras. Respecto de costarricensismo, no aparece registrado en ningún diccionario, y no pasa de ser una sugerencia de neologismo de Ferrero que nunca se llegó a consolidar.

En relación con la compilación de Meléndez (Por la gran puta...), opta por el uso de léxico marcado diafásicamente (en este caso, soez, obsceno, tabú), aunque le faltó la "intuición diferencial-contrastiva" para incluir la expresión en su repertorio, siendo que en el medio costarricense es una construcción interjectiva de sentido unitario -tampoco lo incluye en su repertorio de costarriqueñismos obscenos-. También hay que notar que, a la propuesta/sugerencia de cercanía social que plantea solapadamente al potencial lector, en alguna medida parece querer agregar una nota de complicidad, no solo por lo tabuesco del enunciado que aparece iniciando el título sino también por la fuerza ilocutiva que reflejan los signos de exclamación del enunciado que lo complementa (iqué mal que hablamos!).

Por otro lado, la utilización de léxico marcado no es necesariamente la única estrategia posible para tratar de lograr la aceptación, identificación o empatía del grupo al que pertenecen los potenciales lectores. Otra de las tácticas por medio de los cuales un autor puede tratar de inducir a los lectores a que lo perciban como parte de su grupo es la empleada por Meléndez precisamente en el enunciado final del título, y consiste en el uso la deixis personal incluyente ((iqué mal que hablamos!). El mismo tipo de recurso se puede constatar en otros ámbitos fuera de Costa Rica; lo emplean, por ejemplo, Pedro Geoffroy Rivas, abogado, poeta, periodista y activista político salvadoreño en el título de su repertorio informal de salvadoreñismos El español que hablamos en El Salvador (1982), así como el médico, músico y folclorista nicaragüense César Ramírez Fajardo en su Lengua Madre. (El habla de nuestras madres) (1993) ${ }^{15}$.

\subsection{El prólogo}

Lo que se conoce como prólogo en realidad puede incluir informaciones de muy diversa naturaleza: metadiscursivas (como cuando presentan un panorama global o preliminar de la obra), extradiscursivas (como cuando hablan sobre el autor, su vida, sus méritos), u otras. Dada esta variedad de posibilidades, aquí vamos a entender por prólogo sencillamente el texto o conjunto de textos escritos por el autor u otra persona y previos al cuerpo de la obra.

El prólogo de una obra lexicográfica formal tiene, por otro lado, una particularidad de la que habla Ahumada (1992), que es esta: desde mucho antes de que existiera una disciplina que tuviera como propósito el estudio y propuesta de criterios para la elaboración científica de diccionarios, el prólogo era (y, en principio, aún lo sigue siendo) precisamente el espacio de que disponía el autor de obras lexicográficas para exponer los lineamientos teóricos, metodológicos, expositivos y preceptivos del volumen que estaba presentando.

No es esperable, por supuesto, que escritores con escasos o nulos conocimientos especializados en lexicografía se luzcan con un prólogo estéticamente (es decir, técnicamente) muy acabado, siendo que estos son raros incluso entre los especialistas ${ }^{16}$. En la recopilación de Janer (s.f.), Lenguaje popular y usual de Costa Rica, de hecho es difícil hablar de un prólogo, pues el listado está precedido únicamente por cinco cortas líneas donde lo principal es el agradecimiento del o de los administradores del sitio web hacia la recopiladora. 
En los otros tres casos, que coinciden en justificar el trabajo realizado por sus respectivos autores como un interés por desentrañar la idiosincrasia del costarricense (sus formas particulares de pensar, actuar y concebir el mundo) a partir de sus reflejos en el habla, encontramos las siguientes especificidades en cuanto a procedimientos:

i) En el prólogo de Meléndez (2011), lo más sustancial en cuanto a método es lo referido al criterio de selección del material, que, como era de esperar, es más bien informal; además de su experiencia personal, menciona que: "Muchísimos de los aportes contenidos en este listado han sido suministrados por (...)" y cita los nombres de cinco colaboradores. Sin embargo, en la parte inicial del prólogo menciona otra fuente ${ }^{17}$ : "Del [sic] Gagini [se refiere al Diccionario de costarriqueñismos de Carlos Gagini, 1919] únicamente incorporamos los términos que aún mantienen vigencia en el lenguaje popular, aunque sea por las personas de más edad", aunque no especifica el procedimiento de selección. También indica que: "En el caso en que sean costarriqueñismos aceptados por la Real Academia Española, e incluidos en su diccionario, se precede la definición con la observación: Reg. DRAE". Aunque de esa afirmación no se ha de entender que el DRAE le haya servido como fuente de nomenclatura o como base de contrastación, en general toma en cuenta la acepción registrada en la obra académica para Costa Rica, a veces en forma exacta, a veces con modificaciones y otras veces con comentarios adicionales (en ocasiones incluso valiosos). Sobre los procedimientos para la definición de las demás entradas, afirma que solo de modo esporádico ha consultado otros diccionarios de costarriqueñismos, "ello en aras de aportar mis propias interpretaciones idiomáticas" (Meléndez, op. cit.). ii) En el caso de Giebler (2011), el libro incluye un prólogo con comentarios de cuatro personas resaltando el valor del trabajo llevado a cabo por el autor, tanto por sus descripciones como por lo ameno de la exposición ${ }^{18}$. Le sigue, con carácter preliminar respecto del repertorio glosado de voces, un conjunto de pequeños ensayos que Giebler reúne bajo el título de "Introducción, prefacio... o pa' comenzar, como ustedes lo quieran llamar"; en ellos trata aspectos puntuales del habla que el autor considera característica o usual de los costarricenses, la mayoría relacionados con el léxico, y otros de corte gramatical o pragmático. Los interpreta como reflejo de la idiosincrasia "tica". De los cuatro trabajos estudiados, este es el que tiene la parte prologal (llámese introducción, prefacio, prólogo o de cualquier otro modo) más amplia.

En lo tocante a aspectos procedimentales no es mucho lo que especifica. Uno de los pocos detalles que menciona es la fuente del vocabulario: este proviene de una recolección personal, que originalmente consistió solo en "apuntar costarriqueñismos en unos pedacitos de papel" (Giebler, op. cit.: 11), además de las sugerencias de algunos colaboradores. También hace referencia a la procedencia de las descripciones, las cuales serían de formulación propia $-\mathrm{y}$, en efecto, en su mayoría así parece ser, lo cual a veces se manifiesta en defectos, pero otras veces en aportes de valor-: "Como le fui tomando cariño al asunto, no sólo me puse a definir costarriqueñismos, sino que también «hice cráneo» respecto a las circunstancias en que usamos dichas palabras" (idem).

iii) Por último, Ferrero (2002: xiv), indica que "la escogencia primaria de los términos obedeció a la casualidad y coincidencias que son impredecibles"; la recolección consistió en ir registrando en fichas los términos que iba encontrando durante su 
vida y que concebía como "tiquismos". A estos, según dice, aplicó luego una serie de criterios de selección para evitar el caos y la confusión, de modo que fue eliminando "muchos términos que obedecían a cambios fonéticos" (idem). Para clasificar tales "cambios fonéticos" (16 tipos en total) recurre a notaciones y términos técnicos tomados del campo de la descripción lingüística, como “diptongación” (por ejemplo, en entriega), "reducciones vocálicas" (como en Uropa, ventidós), "relajación de $|\mathrm{x}| \mathrm{y}$ conservación de $|\mathrm{h}|$ " (sin mencionar ejemplos), y otros. Sin embargo, en su exposición de estos criterios de clasificación y exclusión hay diversas inconsistencias que hacen dudar de que realmente comprendiera los conceptos asociados a esa terminología. Es un misterio, por ejemplo, qué quiso decir el autor al hablar de "fonemas de grafías". Otro problema conceptual se pone en evidencia cuando trata secuencias como "-ada" (por ejemplo, en vaqueada), "-ero" (como en zacatero), "-illo" (por ejemplo, en carajillo) y otras, sin mayor análisis, como sufijos.

Otra de las características del prólogo de Ferrero es que incluye algunas (pocas) justificaciones generales sobre el tratamiento que da a los topónimos (que decide excluir), las etimologías y los indigenismos. Las consideraciones, en todo caso, distan mucho de tener un carácter técnico o científico, y casi se pueden reducir a la mención de algunos ejemplos. También señala que consultó, aparentemente como una especie de base de contrastación, el Diccionario de uso del español de Moliner (1966). Además, menciona la consulta de diez diccionarios y vocabularios para verificar el carácter de americanismos de los términos, consultar o verificar etimologías o verificar significados.

En términos generales, y sin una explicación y una ejemplificación suficientes de los criterios y métodos empleados por el autor, es, en todo caso, imposible determinar la rigurosidad con que efectivamente los aplicó. Hay, sin embargo, tal como se ha indicado, señales de que en realidad la aplicación de ciertos conceptos y procedimientos no siempre reflejan un dominio efectivo, por parte del autor, de los conocimientos correspondientes.

\subsection{El cuerpo}

Del cuerpo de definiciones, la inspección se concentrará solamente en los siguientes tres aspectos: a) macroestructura y criterios de lematización, b) tratamiento de la información enciclopédica y c) particularidades de la ejemplificación (si la hay). Para la discusión se tomarán como base de referencia (pero no de evaluación) algunos conceptos y parámetros usuales en la lexicografía tradicional, los cuales se aplicarán por analogía y se tratarán en forma general. Para no recargar la exposición, en este apartado, la mayor parte de las veces que se quiera hacer alusión a alguno de los cuatro repertorios informales estudiados, se hará solamente por el autor. En particular, cuando se transcriba algún "artículo lexicográfico" de alguna de las obras, se dará por entendido que se ubica en el lugar natural según la ordenación alfabética de la nomenclatura.

\subsubsection{Macroestructura y criterios de lematización}

Por analogía con los términos de manejo general en lexicografía formal, hablaremos aquí de macroestructura (conocida también como lectura vertical) para referirnos al tratamiento y disposición de las entradas que componen un repertorio de lexicografía informal de modo que conformen un todo unitario; es decir, la integración de las entradas y la interrelación de unas con otras según determinados criterios.

En cuanto a la macroestructura, las cuatro obras en estudio ordenan las entradas alfabéticamente y en orden ascendente (i. e., en dirección de la $a$ hacia la $z$ ), disposición que de seguro sus autores (y cualquier lector) encuentran natural por ser la del abecedario, así como la de los diccionarios semasiológicos comunes. 
Además, todas coinciden en la lematización de los verbos por la forma en infinitivo, así como en la de los sustantivos y adjetivos por el singular (aunque hay excepciones, como en la entrada que Giebler registra como Cachos, con el significado de "zapatos", en vez Cacho, "zapato"). En el caso de los adjetivos que admiten variación de género, todas lematizan la forma completa correspondiente al masculino; sin embargo, en lo que respecta a la indicación del femenino, los únicos que la incluyen son Giebler, que agrega entre paréntesis el morfema de género femenino, como en Condenillo(a), y Ferrero, que en general agrega la sílaba que contiene tal morfema, como en pachotero, -ra. Hay que notar que en ambos casos la expresión de esta información no siempre es consistente. Giebler a veces la omite, como en Manudo; y lo mismo hace Ferrero, como en salado. Este último a veces también hace una segmentación que transgrede el criterio silábico, como en chiniado, -ada. Meléndez y Janer simplemente obvian la alusión a la forma del femenino, como en Chocho y Jodión, respectivamente.

Otro punto de interés sobre el aspecto estructural es la forma de incluir las frases, locuciones y paremias.

El procedimiento preferido por los glosarios y diccionarios profesionales para registrar unidades pluriverbales consiste en seguir un orden de prioridades basado en una jerarquización (de carácter semántico) de las categorías gramaticales; por ejemplo, sublematizar la frase o locución dentro de la microestructura del primer sustantivo que contenga, o, si no los hay, del primer verbo, etc. ${ }^{19}$. Sin embargo, no hay en realidad motivos para considerar inválida la inclusión de unidades compuestas y complejas directamente en la macroestructura, lematizándolos sencillamente según el orden lineal de lectura. Lo que sí se puede cuestionar, como en todo orden de cosas, es que la aplicación de este criterio no sea consistente en una misma obra.

En nuestro caso, tenemos que, en términos generales, y aunque ninguno explica en ningún momento las pautas para la lematización de las unidades pluriverbales, los cuatro autores son bastante consecuentes con los criterios escogidos tácitamente por cada uno. Sin embargo, las excepciones que se pueden localizar no dejan de mostrar falta de rigurosidad en los procedimientos, la que probablemente sea consecuencia de la falta de dominio de nociones y métodos especializados.

Janer es la que presenta más problemas en decidirse entre lematizar por orden lineal o por categorías focales: la mayor parte de las entradas pluriverbales están lematizadas linealmente, como en Amarrar el perro (en la A) o en Colgar las tenis (en la $\mathrm{C}$ ), pero en no pocas ocasiones las lematiza por el primer sustantivo, como en Agua (metérsele el agua a alguien) (en la A), Barra (hacer barra) o Bola (regar la bola) (estas dos últimas en la B).

Giebler y Meléndez, que también escogen ordenar las construcciones de más de una palabra por el orden de lectura, son más constantes en este criterio, aunque no dejan de presentar ciertos problemas al respecto. Por ejemplo, Giebler, aunque lematiza linealmente (como en Orinar fuera del tarro, en la $\mathrm{O}$ ), en algunos casos toma una decisión diferente, como en "¡Te jodiste!", que incluye en la J, y "Se estalló una llanta", que registra en la E. Si esta decisión surge de la percepción de una escasa carga semántica en los pronombres iniciales, no sería otra cosa que una intuición del criterio antes mencionado basado en la jerarquización de categorías focales. En todo caso, si esa fuera la explicación de esa forma de ordenar tales construcciones, la intuición no se habría extendido a la abstracción de sus formas generales: joderse [alguien] y estallarse [una llanta], respectivamente.

En cuanto a Meléndez, de los autores tratados parece ser el que se da más licencias respecto de la forma y contenido de los artículos de su compilación. Una de las consecuencias estructurales de esas licencias se manifiesta con la introducción solapada, dentro de la microestructura de la locución Puros dieces, (que califica como exp., expresión), de otra locución diferente: "de diez corrido" (mejor que sólo "diez corrido"), la cual, siguiendo su criterio general, debería registrar como entrada aparte): 
Puros dieces: exp. Alguien muy buena gente, o algo muy bueno. Su origen se ubica en el caso de los estudiantes excelentes, que sacan "puros dieces", o sea, las más altas calificaciones. En la jerga estudiantil, a los buenos estudiantes se les dice que son de "diez corrido". En $\boldsymbol{C o l}$., en que la escala de calificación es de 1 a 5 , se les dice "cinco en todo."

Ferrero, por su parte, es el único que decidió lematizar por prioridad categorial, como en ni pica leña ni presta el hacha y hacer hombre a uno, que registra por leña y hombre, respectivamente. Sin embargo, también hay casos en que se desvía de su norma, como en dar cuerda y dar el bendito, ambas en la $\mathrm{D}$, por el verbo dar (pero en entradas aparte).

\subsubsection{Tratamiento de la información enciclopédica}

La complejidad que conlleva realizar una crítica exhaustiva de la informaciones propiamente definicionales de una obra lexicográfica cualquiera, sea formal o informal, no es poca, pues requeriría analizar cada artículo y cada acepción. Solo de ese modo se podría determinar si la obra se ha realizado con seriedad y si está ofreciendo descripciones fidedignas. Dado lo anterior, aquí nos concentraremos en un problema puntual, pero central, de la producción lexicográfica, que es el referido a la inclusión de datos enciclopédicos.

Una de las consignas básicas de la teoría lexicográfica es evitar, en principio, la inclusión de información enciclopédica en las definiciones lexicográficas. La razón es que se supone que no se debería mezclar la descripción lingüística sobre el uso del léxico con referencias extralingüísticas sobre la existencia de las entidades en el mundo.

En relación con los autores que estamos comentando, dos de ellos, Meléndez y Ferrero, no encuentran el menor obstáculo en incluir continuamente datos enciclopédicos en sus descripciones de las palabras, mientras que Janer y Giebler lo hacen solo en raras ocasiones. Sobre Meléndez, lo que más resalta no es tanto que incluya referencias enciclopédicas (pues hasta los diccionarios más prestigiosos recurren en ciertas ocasiones a ello), sino el tono anecdótico con que generalmente son presentadas. Por otro lado, aunque a veces precede tales informaciones de la palabra "Origen" a manera de advertencia, otras veces las entremezcla con las descripciones propiamente lingüísticas, como en el caso de Feria:

Feria: $\boldsymbol{f}$. Ñapa, pequeña recompensa que acostumbraban dar los pulperos a los niños que hacían los mandados de la casa, generalmente un confite, una galleta, un puño de maní o, cuando era más sistematizado, tenían pequeños confites en forma de mini erizo de mar, de diferentes sabores. Los primeros cupones de regalos que se implantaron en $\boldsymbol{C}$. Ric., en forma de estampillas coleccionables en un libro, que luego se cambiaban por regalos, se llamaron "timbre la feria". Luego salieron otros que se llamaron "sellos Botija". Cuando salió este tipo de "ferias" fue una decepción para los niños a quienes nos tocaba ir a comprar a las pulperías. De ahí en adelante, la feria era para los padres y no para los mandaderos.

En cuanto a Ferrero, más que la inclusión de referencias ajenas a la descripción de sentidos y significados, lo llama la atención es que, intercalados entre secuencias de artículos de una, dos o tres líneas, inesperadamente se puede topar el lector con artículos de una, dos o tres páginas que de hecho constituyen verdaderos ensayos de corte histórico, folclorístico o etnográfico. Uno de los casos más extremos es el artículo correspondiente a chorotega, en cuya redacción el autor invierte algo más de ocho páginas -y que no transcribimos aquí por razones obvias -20 .

\subsubsection{Particularidades de la ejemplificación}

Contrariamente a lo que a veces se pueda pensar, el papel de la ejemplificación lexicográfica no es precisar el significado que se ha desarrollado en la definición, pues, si una definición requiere apoyarse en ejemplos para que el contenido semántico de un término sea más comprensible, lo que habría que hacer es mejorar la definición.

La verdadera función de los ejemplos lexicográficos es aclarar el uso contextual de los vocablos; en otras palabras, mostrar la manera 
adecuada en que la palabra se puede o debe insertar en una construcción sintáctica de modo aceptable, gramatical y que refleje el sentido que el lexicógrafo ha pretendido describir.

Otra de sus funciones, estrechamente ligada a la anterior, es evitar la adición de largas y abstractas explicaciones, de índole semántica, pragmática o gramatical, que podrían hacer engorrosa la lectura y comprensión del artículo lexicográfico. Por lo tanto, se espera que los ejemplos, además de esclarecer los usos y restricciones contextuales particulares de cada vocablo, sean claros por sí mismos ${ }^{21}$. Debido a esto, sería una extraña situación la de encontrar en un diccionario de editor aclaraciones a los ejemplos, pues estos más bien se suponen puestos para aclarar los usos.

Uno de los detalles más peculiares observados en dos de las compilaciones que estamos comentando (concretamente en las de Meléndez y Giebler) es precisamente la existencia de ejemplos ampliados con anotaciones, las cuales intentan, ya sea glosar alguna de las voces que aquellos contienen (generalmente la correspondiente al lexema-entrada), o ya sea reinterpretar la formulación considerada como un todo.

Meléndez, quien sólo esporádicamente incorpora ejemplos, presenta varios casos en los que cree necesario decodificar el ejemplo completo mediante lenguaje no marcado, como en el artículo que se transcribe a continuación:

Masticar: $\boldsymbol{t r}$. Tener mucho conocimiento sobre algo, dominar una materia. "Yo mastico el inglish pura vida" (Hablo inglés muy bien). "El tícher mastica esa vara puros dieces" (El profesor domina esa materia perfectamente).

La necesidad de reformular esos ejemplos parece surgir del hecho de que en ellos, aparte del definiendum (la entrada), utiliza otro léxico marcado. Si se toma en cuenta que no son ejemplos reales (tomados de textos), sino construidos por el autor, queda claro que lo que este pretendió fue ilustrar simultáneamente el contexto lingüístico y la situación social de uso.

Giebler, por su parte, ejemplifica la mayor parte de las acepciones, y su apelación al procedimiento de (auto)exégesis es más frecuente.

A veces, quizá para guiar al lector en la sustitución, inserta dentro del ejemplo, entre paréntesis, la glosa correspondiente a la respectiva acepción del lexema, o la glosa más afín, en caso de que haya varias posibilidades. Otras veces, por causas y motivaciones aparentemente análogas a las de Meléndez (según lo comentado antes en relación con Masticar), vierte toda la formulación en términos de formas no marcadas, si bien en ocasiones con mayor libertad léxica y gramatical que aquel. Y aun hay otras ocasiones en que, más que aclarar o glosar el ejemplo, lo que parece estar adjuntando es una interpretación pragmática. Los artículos extraídos a continuación del trabajo de Giebler (2011) ilustran, respectivamente, las tres situaciones indicadas:

Bochinche - Escándalo, pleito, disputa

Ej.: Vieras el bochinche (pleito) que armó el suegro sólo porque llegamos después de las 12 .

Cuerpazo (...) - Cuerpo de hombre o mujer precioso, bien proporcionado

Ej.: José, José, ve’l cuerpazo que va pasando ahí (mira esa mujer con ese cuerpo tan lindo).

Batazo - Acierto proveniente de una suposición o adivinanza

Ej.: ¡Qué bárbaro! ¡Qué batazo! (Lo que estás diciendo proviene de una suposición o sencillamente lo adivinaste. Ni estás seguro de lo que estás diciendo).

Aparte de los aspectos ya señalados, en general la técnica de ejemplificación tiene múltiples problemas de solidez y sistematicidad, los cuales sólo un análisis minucioso y puntual podrá describir. Dado que la visión que pretende el presente trabajo es más bien general, solamente se terminará con algunos detalles que, a pesar de ser puntuales, reflejan problemas en manejo o de comprensión de aspectos básicos del análisis y la descripción lingüísticos, en particular lexicográficos.

Una norma lexicográfica fundamental en la definición de sustantivos, verbos, 
adjetivos y adverbios (esto es, las conocidas como categorías mayores) es que su definición, tomada como unidad, debe hacerse por medio de una unidad léxica o perifrástica de la misma categoría gramatical representada por la entrada. A ese precepto se le conoce como principio de identidad categorial.

En relación con las obras que comentamos, se ha encontrado que en la mayor parte de las definiciones el principio de identidad categorial se aplica adecuadamente, aun dentro del nivel intuitivo en que trabajan sus autores. Ahora bien, aunque hay algunos casos en que la expresión del contenido semántico sí incumple la identidad categorial ${ }^{22}$, en este apartado nos interesa hacer ver que hay otras ocasiones en que un problema análogo se refleja también en las ejemplificaciones. En calidad de muestra, consideremos el artículo correspondiente a Chingue, tomado del trabajo de Janer (op. cit.). En este artículo (y dejando al margen cualquier otro análisis) podemos notar que la autora aplica adecuadamente la identidad categorial en la definición, identificando implícitamente el lexema "chingue" como sustantivo. En cuanto a los ejemplos, el primero se puede considerar eficaz para ilustrar el sentido, en particular porque la prueba de sustitución da resultados aceptables. Sin embargo, es evidente que en el segundo se confunde el lexema-entrada (sustantivo) con otro relacionado con él morfosemánticamente pero de categoría verbal. En síntesis, el segundo ejemplo serviría para ejemplificar el verbo "chingar", pero no debería usarse para ejemplificar el sustantivo "chingue":

Chingue :

Vacilón, algo divertido.

-Ejemplo: ¿Cómo no me voy a enojar?, jesto es serio $y$ ustedes andan en un puro chingue!

-Ejemplo: ¿Es en serio o está chingando?

Otra de las situaciones seleccionadas corresponde a una de las contadas veces en que Ferrero (op. cit.) recurre a la ejemplificación, y se encuentra en la secuencia de ejemplos contextuales introducidos al describir la tercera acepción de "chingo". En primer lugar, hay que resaltar que en realidad lo que hace el autor es integrar los ejemplos contextuales como parte del texto de esa acepción, aparentemente para ayudarse a completar la idea a la vez que para especificar el régimen morfemático que se requiere para que la entrada se interprete en ese sentido $^{23}$. Aunque eso se puede considerar un inconveniente menor, no lo es el hecho de que el tercer ejemplo de la serie no refleja el mismo sentido de chingo que las dos primeras. Parece ser que el autor se dejó confundir por la similitud de la configuración sintáctica de la secuencia "chingo de" en andar chingo de plata con la del patrón de igual forma en chingo de mentiroso y chingo de novia. En otras palabras, confunde el patrón sintáctico con el patrón semántico:

chingo. $m$. adj. (...) [tercera acepción] También suele utilizarse el término para ponderar alguna cosa; según las locuciones Chingo de mentiroso, chingo de novia, Andar chingo de plata, etc.

El último caso que se va a comentar es el de los ejemplos utilizados por Meléndez (op. cit.) como complemento a su definición de maquinazo. Nuevamente, dejando de lado cualquier otro aspecto problemático o inconveniente que haya en las formulaciones, podemos notar que en el primer ejemplo se puede reconocer sin problemas el significado asignado por el autor a la entrada. No obstante, una sencilla aplicación de la prueba de sustitución es suficiente para constatar que el sentido de "maquinazo", tal como es empleado en el segundo ejemplo, no corresponde al que describió ("loco o a punto de estarlo") sino a otro que no describe (p. e.: "descarga eléctrica aplicada en la cabeza a un paciente siquiátrico por medio de...):

Maquinazo: adj. U.t.c.s. Loco o a punto de estarlo."Puta, no le haga caso, ese mae. ¡Es un maquinazo!"; "No sé lo que le pasa, yo creo que está lista pal maquinazo". Origen: El término proviene de los viejos tratamientos siquiátricos del Asilo Chapuí, en donde, con diodos hacían pasar una carga eléctrica por el cerebro, a lo que se llamaba "dar un maquinazo". 


\section{Conclusión}

En este trabajo se han examinado cuatro repertorios informales que intentan describir conjuntos de unidades léxicas que sus autores conciben como propias o características del habla local costarricense. Antes que partir de una descalificación de ese tipo de publicaciones para seguir hacia una descripción, la idea ha sido comenzar por determinar algunas de las formas en que se puede manifestar su carácter informal. Como se podrá entender, en realidad un análisis exhaustivo de esos trabajos conlleva muchos más elementos y más complejidad que lo que aquí se ha intentado. Sin embargo, con lo realizado hemos podido llegar a ciertos rasgos que podrían permitir a un lector, incluso a uno no especializado, tener al menos indicios respecto de si la publicación que tiene ante su vista fue confeccionada a partir de criterios técnicos o no. Algunos de estos rasgos (aunque no necesariamente se encuentren todos en la misma obra) son los siguientes:

a) Siempre son obras "de autor", es decir, su autor se responsabiliza por el proceso y el resultado, y nunca "de editor", en las que el editor o la editorial controlan los atestados del autor y la calidad del producto (además de ser muchas veces trabajo de un equipo); b) el autor no esconde su falta de formación especializada en el estudio y descripción de los hechos de la lengua; c) tampoco ve nada malo en afirmar que el motor de su labor descriptora es la pasión por mostrar cómo la idiosincrasia local se ve reflejada en la lengua, especialmente en el léxico; d) del mismo modo, no ve problema en reconocer que las descripciones se basan en su interpretación personal de los significados o sentidos de las palabras; e) ni que el origen del vocabulario (nomenclatura) procede, al menos en gran parte, de su registro progresivo durante su experiencia de vida; f) la consideración de los vocablos como costarriqueñismos, así como la inclusión de afirmaciones sobre frecuencia, o sobre particularidades diastráticas, diafásicas o diacrónicas, se realiza según el juicio personal del autor; g) ya sea por estrategia o por el franco interés de que sea reconocida su pertenencia a la comunidad de habla local, el autor puede utilizar lenguaje marcado en el título de la obra, en el prólogo o sección preliminar equivalente, y en ocasiones también en el desarrollo de las descripciones (incluyendo los ejemplos); h) la inclusión de información enciclopédica, e incluso de referencias anecdóticas, no representa ningún conflicto dentro del plan general de su obra, aun cuando esos datos aumenten considerablemente la extensión de determinados artículos; i) cuando decide incorporar ejemplos contextuales (ejemplos de uso), a veces les agrega anotaciones a manera de aclaraciones o interpretaciones; por otro lado, las propiedades gramaticales o semánticas del lexema-entrada no siempre se ven reflejadas correctamente en la palabra del ejemplo que se supone las representa, lo que produce incongruencias al aplicar la prueba de sustitución; j) en lo procedimental, no explicita, o no lo hace clara y suficientemente, las pautas y criterios para la confección de la obra a nivel macro ni microestructural; k) generalmente (aunque no siempre de forma consistente) lematiza las unidades pruriverbales directamente en la macroestructura según el orden lineal de lectura; 1) de hecho, los criterios (ya sea los pocos que establece abiertamente o el grueso, formado por los que utiliza tácitamente) no se aplican uniformemente a lo largo de la obra; m) aun siendo claro que su preparación formal no está dirigida al análisis y descripción de las características lingüísticas o sociales del léxico, en ocasiones decide agregar a las entradas anotaciones de uno $\mathrm{u}$ otro tipo para especificar el uso de las unidades que explica; al hacer esto, cae en múltiples inconsistencias respecto a conceptos básicos de la teoría lingüística. 
En síntesis, se ha mostrado que, aparte de ciertas peculiaridades relacionadas más bien con el estilo y la selección de los contenidos que se consideran adecuados -aspectos que, en principio, no tendrían por qué tener implicaciones graves para la transmisión de información definicional- en los repertorios que hemos examinado existen múltiples errores, inexactitudes, imprecisiones e inconsistencias en el nivel de la forma, tanto a nivel de lectura vertical (macroestructura) como de lectura horizontal (microestructura). Es muy probable que la mayoría de esos problemas surjan por el afán de los escritores de repertorios informales de copiar las prácticas de los lexicógrafos aun sin tener conocimiento de cómo, por qué y para qué estos hacen lo que hacen. De esta forma de obrar, que invade los dominios especializados de áreas de acción diferentes que la propia, no se pueden esperar buenos resultados, igual que no se puede esperar un trabajo consistente y seguro de quien hace una instalación eléctrica sin ser electricista, ingeniero o similar. Ese modo de hacer, cuya finalidad es probablemente que sus trabajos sean mejor acogidos por tener una presentación similar a la de los modelos más prestigiosos, como lo son, en el imaginario colectivo, los diccionarios y afines, parece sobrepasar la capacidad de intuición de sus autores relativa a lo que es una acertada descripción lingüística de las palabras.

No obstante lo anterior, creemos que las ideas de Pérez (2007) merecen ser tomadas en cuenta, discutidas mediante una crítica fundamentada y aplicadas apenas hayan logrado el suficiente desarrollo y solidez conceptual. Y es que, quiérase o no, lo cierto es que los repertorios informales, en particular los regionalistas, no son solo un fenómeno real, sino que son un fenómeno social que efectivamente puede incidir en la formación (o deformación) y en la información (o desinformación) de muchas personas. Este tipo de repertorios existió antes que los diccionarios modernos, es decir, que las obras lexicográficas confeccionadas con mayor rigor y sistematización, y siguen existiendo paralelamente a ellos, igual que muchas actividades artesanales siguen existiendo a pesar de que, en cuanto a rigor y conocimiento, ya han sido superadas por técnicas, tecnologías y ciencias formalizadas - pensemos, por ejemplo, en la medicina popular respecto de la medicina científica-.

Son precisamente los potenciales efectos, tanto positivos como negativos, que puedan tener sobre sus lectores, los que justifican que se realice un estudio profundo de esas producciones, y no solo en cuanto a obras individuales, sino también en cuanto que fenómeno global. Descubrir, por ejemplo, por qué hay personas que consultan esos tipos de materiales, e incluso que los compran, cuando se publican en forma impresa -recordemos que el libro de Giebler va por su cuarta edición- es uno de los muchos aspectos que vale la pena ser investigado. Tampoco es conveniente generalizar a todas las obras los problemas ubicados en algunas, y la educación del público para que pueda reconocer cuando está ante una "buena" compilación (ya sea formal, como un diccionario, enciclopedia o glosario "de editor", o ya sea informal) será probablemente el mejor método para que la presencia de esas publicaciones no tenga efectos adversos en el conocimiento social.

Con respecto a la valoración de los trabajos de carácter informal (en el sentido en que hemos venido aplicando esta última noción), es claro que, por el afán de obtener datos fidedignos en lo tocante a los contenidos léxicos, la lexicografía estricta ha tendido a favorecer el perfil de los autores que, aun careciendo de formación lexicográfica, tienen (en principio) conocimiento sobre el área de especialidad del léxico que describen. Por ejemplo: el biólogo que hace un glosario de biología, el pintor que hace un glosario sobre pintura, el escritor o literato que hace uno sobre el léxico de su novela, y así sucesivamente.

En realidad hay razones muy válidas para ver con desconfianza un glosario de orfebrería hecho por un geólogo de profesión, o uno de pintura hecho por un médico, o uno de linotipia escrito por un actor de teatro -a no ser, claro está, que el geólogo fuera a la vez orfebre, o el médico fuera también pintor o el actor a la vez linotipista, con lo cual caerían más bien en el caso anterior-. 
Sin embargo, podemos preguntarnos si hay igual justicia en valorar como sospechosos o totalmente inútiles, antes de un examen particularizado, los trabajos de regionalismos publicados por médicos, ingenieros, economistas, maestros o incluso por personas que no han acreditado suficientemente su profesión u ocupación, siendo así que la competencia lingüística del hablante de una variedad de lengua lo hace, en un sentido muy real, experto en el uso de esa variedad -aun cuando ese sentido sea diferente de aquel con que catalogamos como experto a quien se ha formado en una disciplina determinada, y suponiendo que los compiladores sean hablantes de la respectiva variedad-.

$\mathrm{Si}$, por ejemplo, se llegara a determinar que el problema de una obra está en la calidad de los métodos de descripción empleados, se podría pensar en aprovechar la información que incluya sobre los sentidos y usos de las unidades léxicas extrayéndola, ya sea por medios tradicionales o automatizados, para efectos de ser usada, previa revisión, afinamiento y reformulación, por el lexicógrafo profesional en su trabajo. Este proceder, en todo caso, se encuentra aceptado por los dos teóricos que hemos tomado como referencia (cf. Ahumada, 2000 y Pérez, 2007). Vale la pena preguntarse, entre otras cosas, si el profesional en análisis y descripción de la lengua seguiría mirando con tanta desconfianza estos repertorios en caso de que se presentaran al lector con formato de ensayo, conteniendo las mismas descripciones de los mismos vocablos pero intercaladas entre anécdotas, recuentos históricos, valoraciones personales u otros tipos de comentarios. ¿Seguiría considerándolos como invasivos?

Hay que tomar en cuenta, a propósito de esto, que la extracción automatizada de conocimientos definicionales a partir de corpus textuales, por medio del reconocimiento de patrones lingüísticos y la aplicación de algoritmos, es una línea de investigación que toma cada vez más fuerza. Estos conocimientos definicionales, que no necesariamente están estructurados a manera de definiciones tal como se entienden tradicionalmente, corresponderían a información esencial relativa a las unidades de un conjunto léxico. A pesar de los muchos problemas procedimentales que pudieran presentar los repertorios de los que tratamos, de seguro el caso de aquellos que se puedan considerar tan caóticos que no sean en absoluto aprovechables es más bien raro. Más bien, si pensamos en que la mayoría de esos textos ya están al menos semiestructurados, ya habría parte del trabajo adelantado.

$\mathrm{Ni}$ ignorar esas producciones comunicativas, ni atacarlas como a una plaga, deberían ser las mejores salidas, porque, así como la medicina en determinadas ocasiones ha verificado la funcionalidad de remedios populares tradicionales, de igual modo la lexicografía podría, eventualmente (aunque, por supuesto, tampoco necesariamente), aprender algo de ellas. Estamos convencidos de que el estudio serio y sistemático de esas producciones podría llevar incluso a reflejar aspectos en que la lexicografía de mayor reconocimiento podría mejorarse a sí misma, ya sea revisando sus métodos y procedimientos o incluso revisando el alcance de sus problemáticas tradicionales. Por ejemplo, una de las consecuencias de la escasa discusión conceptual sobre el fenómeno de los repertorios informales es que hay aún mucha falta de uniformidad y sistematización en considerar cuáles trabajos caen dentro de las categorías de glosarios escondidos (en el sentido explicado por Ahumada, 2000), de glosarios en general, de repertorios informalizados (en el sentido de Pérez, 2007), de léxicos, de vocabularios, de obras de lexicografía aficionada, etc. Pero, más allá de una mera reconceptualización tipológica, para dedicarse al análisis sistemático de cualquiera de esas manifestaciones es necesario comenzar por determinar con precisión el objeto de estudio, sus efectos en el sistema-universo de las obras lexicográficas, sus efectos en la transmisión de conocimientos definicionales, etc.

En cuanto a los problemas e inconsistencias quepuedahaberen las producciones lexicográficas informales, es muy posible, como ya se ha sugerido, que muchos de ellos tengan su origen precisamente en el desacierto de querer copiar la formalidad de las obras consideradas como referencias de prestigio. Tal vez en ese proceso 
la actividad informal pierde la naturalidad $\mathrm{y}$ espontaneidad de sus descripciones, que podrían ser sus mayores activos.

Aunque en ocasiones las intuiciones metalingüísticas de sus autores sobre los contenidos semánticos de la unidades léxicas den como resultado descripciones más o menos rústicas, problemáticas o incluso del todo inválidas, otras veces pueden constituir materiales muy finos y valiosos para el estudio lexicográfico, lexicológico, filológico, gramatical o pragmático, entre otros. En fin, no solo la lexicografía podría beneficiarse, para sus propósitos propios, de un análisis crítico y fundamentado de esos trabajos, sino que, en la medida en que se reconozca tal actividad informal como fenómeno social y comunicativo, su estudio también podría generar conocimientos de interés para una metalexicografía de alcances amplios.

\section{Notas}

Sin embargo, no deja de ser paradójico que las nociones de lexicografía, lexicografía teórica, lexicografía práctica, metalexicografía, lexicología y otras relacionadas, así como las fronteras entre ellas, no parecen estar suficientemente claras aun para los mismos teóricos. Por ejemplo, Martínez de Sousa (1995: 224) define lexicografía, en su primera acepción, como "Arte y técnica de elaborar diccionarios" y, en la segunda, como "Estudio del léxico de una lengua". La segunda acepción es más bien obscura en cuanto a los límites entre lexicografía y lexicología, definida esta por el mismo autor (op. cit.: 254) como "Ciencia que estudia el léxico de una lengua en su aspecto sincrónico" - ¿significa esto que la lexicografía se encarga de su aspecto diacrónico, tal vez?-. Por otro lado, para la entrada correspondiente a lexicología aplicada, el autor simplemente remite a lexicografía. No obstante lo confuso de tal panorama terminológico, normalmente en una definición de lexicografía podemos esperar encontrar palabras como arte, técnica, disciplina, ciencia, léxico, diccionario... La idea subyacente parece girar en torno a la existencia de procedimientos estandarizados (y, por lo tanto, no arbitrarios ni caprichosos) para confeccionar ciertas obras entre las que están, en posición prototípica, aquellas que se conocen como "diccionarios". Sea que estos traten sobre léxico general (estándar, no marcado) o sobre cualquier conjunto léxico seleccionado según determinados criterios o restricciones de uso, la lexicografía (incluso sin diferenciar entre su vertiente práctica y su vertiente teórica) sería la encargada de proveer pautas y herramientas conceptuales para que las obras producidas sean coherentes y funcionales.

2 No obstante, un cuerpo disciplinario y de conocimientos equivalente a la lexicografía, pero concebido para amparar el tratamiento de los glosarios y otras obras más afines a estos que a los diccionarios, no ha pasado de ser un mero constructo teórico que nunca ha tenido referente en la realidad. Tan es así, que una palabra que nombre tal supuesta disciplina -vista como sistema teórico o prescriptivo, pues la práctica de hacer glosarios y similares es más antigua que la de hacer diccionarios, al menos considerados en su sentido moderno- es difícil de hallar. Es el caso del término "lexigrafía", que, a pesar de que nunca prosperó en el uso, Martínez de Sousa (op. cit.: 255) menciona y define como "arte y técnica de elaborar glosarios y vocabularios, por oposición a la lexicografía, que elabora diccionarios", agregando seguidamente que "esta palabra no tiene registro en las obras que tratan de lexicografía ni en los diccionarios (de lengua o enciclopédicos); la recoge únicamente Alvar Ezquerra (...), quien la toma de Bernard Quemada (...)”. En síntesis, “(...) la palabra lexigrafía carece de entidad y uso" (idem).

3 A diferencia de Ahumada (op. cit.), la posición de Pérez (2007) es más categórica al respecto: "La amplitud de opciones queda a la vista desde el momento en que no solo entendemos por lexicografía al diccionario como el repertorio formalizado por excelencia, sino también los textos marginales e inadvertidos con relativa formalización diccionariológica y los repertorios léxicos infusos sin ningún tipo de formalización (a estos últimos, la investigación lexicográfica los dotará de esa forma, gestando el lexicógrafo el texto y haciéndolo nacer para la historia y estudio de la disciplina)" (Pérez, 2007: 142).

4 La condición de que existan restricciones de uso permite oponer tales repertorios a los que recogen léxico estándar, es decir, léxico general o no marcado. Para incluir esta condición tomamos en cuenta las consideraciones expuestas por Ahumada (2000), aunque, en todo caso, y según mencionamos en un punto anterior, los motivos obedecen más a cuestiones fácticas que teóricas, concretamente a la dificultad de hallar obras sobre léxico general y estructura parecida a la de diccionarios escritas 
por personas sin formación especializada en descripción lingüística. Pareciera como si existiera un reconocimiento tácito de que tal labor debe dejarse exclusivamente en manos de especialistas, pero que el tratamiento de los léxicos especiales (marcados) no tiene la misma limitación.

Aunque quien hable de una "lexicografía aficionada" puede querer resaltar simplemente su carácter no profesional (es decir, una actividad realizada sin conocimientos especializados), desligar tal expresión de una valoración a priori negativa puede ser difícil. Nótese, por ejemplo, la connotación con que Ahumada (2000: 52-53) emplea "aficionados" en el siguiente texto: "Para el profano, hacer lexicografía regional, esto es, confeccionar el inventario de aquellas palabras que él siente como exclusivas, es la actividad más simple y sencilla a la que podamos enfrentarnos. Basta sólo con comprobar si el uso que él y sus vecinos hacen de la lengua está registrado o no en un diccionario general. (...) Entender de manera tan primitiva el trabajo del lexicógrafo es el motivo principal que ha llevado a no pocos aficionados a acercarse a la lexicografía regional”.

Las definiciones estipulativas son características de los ámbitos especializados. El contenido de la definición declara qué se ha de entender por un término en un contexto dado. Ese contexto puede ser una ciencia, una tecnología, un libro, una ley, etc.

Determinar si esta exclusión es un efecto innecesario o indeseado de la condición de autonomía es algo que se podría considerar como pendiente de mayor discusión.

Para ambos tipos de soporte, de seguro una búsqueda minuciosa revelaría una buena cantidad de pequeñas obras de menor alcance confeccionadas para ámbitos más limitados.

10 Véanse, por ejemplo, los datos sobre el autor incluidos en la sección "Escritores" del sitio web de la Editorial Costa Rica, http://www.editorialcostarica. com, y la reseña de Ugalde (2010) en http://www. clubdelibros.com.

11 V. el ensayo Biografía de Meléndez en su sitio http:// dmelende.wordpress.com/.
Esto es, al menos, lo que interpretamos del prólogo del Ing. Mauricio Ávalos, quien habla de “(...) su lado «alemán-ingenieril»” (Giebler, op. cit.: 10).

Enotras páginas de sumismo blog, Meléndezpresenta otros repertorios de voces del área costarricense, agrupadas con base en especificidades adicionales. Los nombres de estas secciones describen bien los respectivos contenidos: "Babel de plantas, frutas y verduras: ¿llegaremos a ponernos de acuerdo?”, "Gastronomía tica" y "Costarriqueñismos obscenos y tabús". Con respecto a las palabras de esta última colección, indica el autor que: "Se ha preferido separarlas del listado de costarriqueñismos, pues algunas personas, a quienes dicho destape aún incomoda, han dejado constancia de su protesta, pues les parecen grotescas" (Meléndez, http:// dmelende.wordpress.com/). Es posible que el autor, por motivos en los que no es esta la ocasión para ahondar, decidiera mantener en el trabajo que analizamos el título original de antes de la escisión. Por otro lado, se puede notar que la situación es la inversa de la que describe Pordo Dapena (2002: 172), en el sentido de que es común que los autores de diccionarios de léxicos obscenos o tabúes eviten la vulgaridad en sus títulos bautizando sus recopilaciones como "diccionarios secretos", "diccionarios de términos malsonantes", o cosas parecidas.

En relación con la credibilidad, es posible que la falacia de autoridad, que tantas veces pasa desapercibida en el imaginario popular, en alguna medida también juegue a favor de los autores de esos textos. Esta falacia consiste en proyectar en un área de acción la autoridad que alguien tiene en otra muy diferente.

Las negritas no se encuentran en los títulos originales. Por otro lado, para Geoffroy Rivas, cf. la reseña biográfica de Lara Martínez (http://archivo. contrapunto.com). Para Ramírez Fajardo, cf. la que aparece en el sitio de Orgullos Nicas (http://www. orgullosnicas.com/).

Cf. Ahumada (1992: 17): "Generalmente, un buen diccionario va precedido de un buen prólogo, entendiendo por «buen prólogo» aquel que recoge y justifica los siguientes puntos básicos:

(a) El material que ha servido de base para el corpus de ejemplos.

(b) El criterio de selección que ha regido las entradas y la utilización del corpus. 
(c) Los principios seguidos en la redacción de las definiciones.

(d) La consideración que le merecen las diferencias diatópicas, diastráticas y diafásicas.

(e) El problema de las terminologías.

(f) Y, por último, la orientación gramatical de sus planteamientos.

Ahora bien, antes que el buen prólogo es mucho más frecuente el mal prólogo. Esto es así porque abundan más los malos que los buenos diccionarios."

El prólogo de esta obra está en realidad dividido, pues al texto que aparece al inicio bien podría unírsele, siempre con carácter de prólogo, el que aparece después del listado. Es, por llamarlo de algún modo, una especie de prólogo escindido.

Uno de los comentarios que no aparecían en las ediciones anteriores es transcripción de la reseña que Alberto Cañas (abogado, periodista, político y literato; miembro de número de la Academia Costarricense de la Lengua) publicó en la columna Chisporroteos del diario La República (2010, 8 de diciembre) con motivo de la publicación de la $3^{\mathrm{a}}$ edición. El grueso de la nota, colmada de elogios, dice así: "Algunas personas podrían pensar que es un libro similar a los tres diccionarios de costarriqueñismos que han visto la luz en nuestra patria, pero se equivocarán. Este libro no es una recopilación de las palabras que usamos sino un intento muy bien logrado de estudiar y analizar de donde vienen, cómo las usamos y por qué las usamos. / Y no se limita, como los diccionarios, a palabras con su definición. Indaga su origen, e incluye frases hechas, expresiones compuestas, fórmulas, todo lo que tiene que ver con nuestra manera de hablar. / No conozco un estudio más serio ni más completo sobre nuestra manera de expresarnos, que es, indefectiblemente, un estudio de nuestra manera de ser, de nuestro espíritu y de nuestra manera de pensar. Pues para Giebler Simonet, el habla es un reflejo de la idiosincrasia nacional, lo que convierte su libro en un estupendo, imprescindible estudio sobre lo que los costarricenses somos, pretendemos y vivimos. / Busque el lector este libro y agradézcame mientras viva la recomendación que le estoy haciendo" (Cañas, op. cit.).

Por microestructura se entiende el conjunto de informaciones relativas a una entrada, organizadas según determinados criterios de normalización para formar, junto con la entrada, una unidad informativa.

En su prólogo, Ferrero (op. cit.: xii) afirma: "Me mueve ir a la totalidad de los aspectos intelectuales, materiales, emocionales y espirituales más significantes y singulares de una sociedad o grupo social. Y, porque al ahondar en el pasado, voy a la cultura espiritual o material de nuestros ascendientes, especialmente de las tierras altas centrales y de la provincia de Guanacaste". Al parecer, la pasión por la descripción de especificidades culturales lo hace dar poca importancia al desbalance extremo en la extensión de los diversos artículos.

21 Sin embargo, ni aun los diccionarios de mayor trayectoria son inmunes a los problemas de ejemplificación, como se puede constatar en el siguiente caso tomado del DRAE (2001): "parentético, ca. adj. (...) 2. Se dice de las expresiones que constituyen incisos. La clase política, creo yo, no está a la altura de lo que esperamos de ella». Como se puede observar, el "ejemplo" en la segunda acepción no fue incorporado para ilustrar el uso contextual, sino más bien el concepto definido -o, al menos, ese fue el resultado-. Debido a que el lexema definido no aparece en el ejemplo, como se supone debería ser, es imposible aplicar la prueba de sustitución, que consiste en reemplazar, en un enunciado u oración, determinada palabra por su definición y verificar que se conserva el sentido.

22 Cf. por ejemplo, en Ferrero (op. cit: artículo correspondiente), la descripción de "empunchado": empunchado, -da. (p.p. de empunchar o empuncharse). adj. Trabajar con ahínco, a estudiar, a emprender un deporte.

23 Compárese con la manera usual de informar sobre el régimen morfemático en el DRAE (2001), como en el caso siguiente: "tener. (...) 9. Juzgar, reputar, considerar. Tener a alguien POR rico. Tener A gala, A honra algo. U. t. c. prnl. Tenerse POR sabio". Aunque es un procedimiento parecido al seguido por Ferrero, no es idéntico, en particular porque en este caso los ejemplos siguen siendo unidades independientes.

\section{Bibliografía}

$$
\text { Ahumada Lara, Ignacio (ed.). (1992). }
$$
Diccionarios españoles: Contenido y 
aplicaciones. [Lecciones del I Seminario de Lexicografía Hispánica, Facultad de Humanidades, Jaén, 21 a 24 de enero de 1991]. Jaén, España: Seminario de Lexicografía Hispánica, Facultad de Humanidades.

Ahumada Lara, Ignacio. (1992). "J. FernándezSevilla y la lexicografía teórica española”. En: Ahumada Lara (ed.), 1992: 13-33.

Ahumada Lara, Ignacio. (2000). Estudios de lexicografía regional del español. Jaén: Universidad Nacional de Educación a Distancia, Centro Asociado de la Provincia de Jaén.

Cañas, Alberto F. (2010). Chisporroteos. Recuperado el 07-05-2012 de http://www. larepublica.net/app/cms/www/index. php?pk_articulo=41780.

Editorial Costa Rica. (s.f.). Luis Ferrero Acosta. Recuperado el 17-09-2012 de http:// www.editorialcostarica.com/escritores. cfm?detalle $=1013$.

Ferrero Acosta, Luis. (2002). Mil y tantos tiquismos: costarricensismos (1 ${ }^{\mathrm{a}}$. ed.). San José, C.R.: Editorial Universidad Estatal a Distancia.

Geoffroy Rivas, Pedro. (1982). El español que hablamos en El Salvador (5a. ed.). San Salvador, El Salvador: Dirección de Publicaciones, Ministerio de Educación.

Giebler Simonet, Alf. A. (2011). A lo tico: Costarriqueñismos y otras vainas (4 ${ }^{\mathrm{a}}$. ed.). San José: Ediciones Jadine. [1 $1^{\mathrm{a}}$. edición: 2003, San José: Diseños Precisos].

Janer, Silvia. Lenguaje popular y usual de Costa Rica. Recuperado el 18/09/2012 de http:// www.costarica. 20 m.com/diccionario. html.
Labov, W. (1966). The Social Stratification of English in New York City. Washington D.C.: Center for Applied Linguistics.

Lara Martínez, Rafael. (s.f.). Pedro Geoffroy Rivas [en línea]. Recuperado el 28/09/2012 de http://archivo.contrapunto.com.sv/ index 2.php?option $=$ com_content\&do pdf $=1 \& \mathrm{id}=388$.

Martínez de Sousa, José. (1995). Diccionario de lexicografía práctica. Barcelona: Biblograf.

Meléndez Howell, Dennis. (s.f.). Biografía. Recuperado el 14/09/2012 de http:// dmelende.wordpress.com/2009/08/01/ biografia/.

Meléndez Howell, Dennis. (s.f.). Babel de plantas, frutas y verduras: ¿llegaremos a ponernos de acuerdo? Recuperado el 13/09/2012 de http://dmelende.wordpress. com/2009/08/07/babel-de-plantas-frutasy-verduras-\%C2\%BFllegaremos-aponernos-de-acuerdo/.

Meléndez Howell, Dennis. (s.f.). Costarriqueñismos obscenos y tabús [en línea]. Recuperado el 13/09/2012 de http:// dmelende.wordpress.com/2011/01/01/ costarriquenismos-obscenos-sobre-sexoy-organos-sexuales/.

Meléndez Howell, Dennis. (s.f.). Gastronomía tica. Recuperado el 13/09/2012 de http:// dmelende.wordpress.com/2009/08/07/ terminos-de-la-gastronomia-tica/.

Meléndez Howell, Dennis. (2011). Por la gran puta, iqué mal que hablamos! Recuperado el 13/09/2012 de http://dmelende. wordpress.com/2011/01/01/por-la-granputa- $\% \mathrm{C} 2 \%$ Alque-mal-que-hablamos- $2 /$. 
Orgullos Nicas. s.f. César Ramírez Fajardo [en línea]. Recuperado el 28/09/2012 de http:// www.orgullosnicas.com/cantantes-ycompositores/cesar-ramirez-fajardo.html.

Pérez, Francisco Javier. (2007). "Sobre los glosarios literarios y su significación en la investigación lexicográfica". Boletín de Filología XLII: 137 - 155.

Porto Dapena, José-Álvaro. (2002). Manual de técnica lexicográfica. Madrid, España: Arco/ Libros.

Ramírez Fajardo, César A. (1993). Lengua Madre. (El habla de nuestras madres) ( $3^{\mathrm{a}}$. ed.). Nicaragua: Lithoroma Industrial.
Real Academia Española. (2001). Diccionario de la lengua española (22a. ed.). Madrid: Real Academia Española/Espasa Calpe.

Trudgill, P.J. (1972). "Sex, Covert Prestige and Linguistic Change in the Urban British English of Norwich". Language in Society I: $179-195$.

Trudgill, P.J. (1992). Introducing Language and Society. Londres: Penguin.

Ugalde, Evelyn. (2010). Luis Ferrero Acosta. Recuperado el 14/09/2012 de http://www. clubdelibros.com/biografias/175-luisferrero-acosta-.html. 
